\title{
Prognostic and diagnostic potential of isocitrate dehydrogenase 1 in esophageal squamous cell carcinoma
}

\author{
Xuan Chen ${ }^{1}$, Qingbao Li $^{2}$, Cong Wang ${ }^{1}$, Wenzhe $X u^{3}$, Lihui Han ${ }^{1}$, Yuan Liu ${ }^{1}$, Bowen \\ Liu $^{1}$, Shanghui Guan ${ }^{1}$, Bingxu Tan ${ }^{1}$, Jianbo Wang ${ }^{1}$, Nana Wang ${ }^{1}$, Qingxu Song ${ }^{1}$, \\ Yibin Jia ${ }^{1}$, Jianzhen Wang ${ }^{1}$, Linli Zhao ${ }^{1}$, Yufeng Cheng ${ }^{1}$ \\ ${ }^{1}$ Department of Radiation Oncology, Qilu Hospital of Shandong University, Jinan, Shandong, 250012, China \\ ${ }^{2}$ Department of Cardiac Surgery, Shandong Provincial Hospital Affiliated to Shandong University, Jinan, Shandong, 250021, \\ China \\ ${ }^{3}$ Department of Neurosurgery, Qilu Hospital of Shandong University, Jinan, Shandong, 250012, China
}

Correspondence to: Yufeng Cheng, email: qiluchengyufeng@163.com

Keywords: ESCC, IDH1, protein expression, diagnosis, prognosis

Received: July 28, $2016 \quad$ Accepted: November 09, 2016

Published: November 15, 2016

\section{ABSTRACT}

We aimed to investigate the pattern of expression and clinical significance of isocitrate dehydrogenase 1(IDH1) in esophageal squamous cell carcinoma (ESCC). The IDH1 expression was determined by quantitative real-time polymerase chain reaction, immunohistochemistry, and Western blot analysis using 38 pairs of frozen tissues. Enzyme-linked immunosorbent assay was employed to measure 67 pairs of serum samples from patients and their controls to evaluate its diagnostic value. Immunohistochemistry analysis of 111 formalin-fixed paraffin embedded tissue samples was conducted for explaining its prognostic value. After shRNA transfection, CCK8 and clonal efficiency assays were carried on for verifying the function of IDH1 in vitro. Increased expression at mRNA $(P<0.001)$ and protein levels (immunohistochemistry: $P<0.001$, Western blot analysis: $P<0.001$ ) were observed. Similarly, the IDH1 expression in serum from patients with ESCC was significantly upregulated relative to that from healthy controls $(P<0.001)$. KaplanMeier curve indicated that IDH1 upregulation predicted worse overall survival (OS) and progression-free survival (PFS). Univariate and multivariate analyses identified IDH1 expression as an independent prognostic factor for OS and PFS. Furthermore, OD450 values and colony numbers were decreased in sh-IDH1 groups (all $P<0.05$ ). In conclusion, IDH1 is upregulated in patients with ESCC and can be used as a good potential biomarker for diagnosis and prognosis.

\section{INTRODUCTION}

Esophageal cancer is the sixth main cause of cancerrelated mortality and the eighth most common cancer worldwide [1]. The high-risk geographic region, referred to as the "esophageal cancer belt," extends from Northern Iran to North Central China through Central Asia. In this region, more than $90 \%$ of the cases are identified as esophageal squamous cell carcinoma (ESCC), in contrast to only $26 \%$ in the United States [3]. Advanced techniques in the diagnosis and treatment of esophageal cancer failed to improve the prognosis. The 5-year overall survival rate of patients with ESCC ranges from $15 \%$ to
$25 \%$ [4]. Biological factors are superior to endoscopy in assessing the malignant behavior of ESCC in terms of invasiveness, cost, and testability. A number of tumorspecific proteins have been identified as tumor markers for various cancers. These proteins include cancer antigen 125 (CA125) in ovarian cancer, alpha-fetoprotein (AFP) in liver cancer, carcinoembryonic antigen (CEA) in colon cancer, and prostate-specific antigen (PSA) in prostate cancer. No superior biomarkers have thus far been found in ESCC patients. Several proteins have been identified as key molecules in signal transduction pathways of ESCC development, such as vascular endothelial growth factor (VEGF)-C, peptide antigen, CEA. However, insufficient 
sensitivity and specificity parameters limit the application of these biomarkers in the early diagnosis of ESCC [6]. New biomarkers with combined high sensitivity and good specificity for the diagnosis and prognosis in ESCC can provide enhanced clinical benefits.

Metabolic plasticity is regarded as a hallmark of cancer [7]. Several transformational metabolic features are observed quite generally across various types of cancer cells [8]. Cancer cell metabolism is characterized by the ability of acquiring essential nutrients from a frequently innutritious environment and using these nutrients to both maintain the vitality of its own and build greater biomass [9]. The isocitrate dehydrogenase (IDH) family comprise the rate-limiting enzymes in the tricarboxylic acid (TCA) cycle and include 3 members (IDH1, IDH2, and IDH3) that convert isocitrate to $\alpha$-ketoglutarate $(\alpha-K G)$ by oxidative decarboxylation [10]. $\alpha-\mathrm{KG}$ is an intermediate of the TCA cycle and a cosubstrate of a number of dioxygenase reactions in the cytoplasm and the nucleus [11]. IDH also produces non-mitochondrial NADPH. NADPH as a required component to handle redox stress is crucial for tumor cell growth [12]. IDH not only participates in lipid biosynthesis but acts as an essential antioxidant as well [13]. Cancer cells exhibit persistently high levels of reactive oxygen species (ROS) because of genetic, metabolic and microenvironmental alterations including hypoxia, as well as crosstalk between cancer and immune cells [14]. These ROS-induced dysfunctions are compensated by an upregulated antioxidative capability of these cancer cells [15]. IDH, together with a long-lasting endogenous substrate (glutamate), mainly contributes to the regeneration of reduced glutathione (GSH), which is a critically important antioxidative system against oxidative damage and xenobiotic toxicity to cells by providing NADPH $[16,17]$. Moreover, the inhibition of antioxidative systems can kill cancer cells synergistically with radiotherapy and chemotherapy both in vitro and in vivo [18].

IDH1 plays driving roles in the metabolism of glucose, fatty acids, and glutamine as well as the maintenance of cellular redox status; IDH1 is located in the cytoplasm and peroxisomes [19]. Recent studies on IDH1 in cancers have primarily focused on the mutations of the IDH1 gene. IDH1 mutations were found in low-grade glioma and secondary glioblastoma, acute myeloid leukemia, chondrosarcoma, intrahepatic cholangiocarcinoma, and melanoma [22-24].

The aforementioned studies on the IDH1 gene indicate that IDH1 mutation may significanty affect tumorigenesis and tumor progression. IDH-mutated cancers cannot be reduced to homozygosity and retain one $I D H$ wild-type allele. Ward et al. suggested and then validated that wild-type $I D H 1$ promotes cell growth and proliferation [25]. Aberrant protein expression, as the primary functional gene output, complements genome initiatives and is an important phenotypic characteristic of cancer. The association of protein biomarkers with clinical characteristics and outcomes of cancer patients may elucidate the underlying molecular mechanisms of cancer initiation and progression [26]. Studies on wild-type IDH1 protein as a diagnostic and prognostic biomarker remain inadequate. IDH1 protein has been identified as a novel biomarker for the diagnosis of non-small cell lung cancer [27]. A study using genome-wide RNA-Seq indicates that IDH1 expression is higher in ESCC tissues than in normal tissues [28]. However, the protein expression of IDH1 in ESCC and its correlation with 5-year overall survival (OS) rates and progression-free survival (PFS) are undetermined.

In the current study, we compared the expression of IDH1 in the tumor tissue with that in the paracancerous tissue by quantitative real-time PCR (qRT-PCR), immunohistochemistry, and Western blot analysis. The serum expression in patients and healthy controls were used to assess the value of IDH1 as a diagnostic biomarker. Moreover, the association of IDH1 with the clinicopathological characteristics of patients with ESCC and the prognostic value of IDH1 were analyzed. CCK8 and clonal efficiency assays were used for observing if IDH1 could affect growth and proliferation of ESCC cells.

\section{RESULTS}

\section{IDH1 expression in frozen tissues}

IDH1 expression was analyzed by IHC, qRT-PCR, and Western blot analysis. The IDH1 expression in the formalin-fixed paraffin embedded (FFPE) tissue samples was determined by IHC. The IDH1 protein was primarily distributed in the cytoplasm of ESCC cells (Figure 1). Cancerous samples showed $22(+++), 8(++), 6(+)$, and $2(-)$, whereas paracancerous tissues showed $34(-)$ and 4 $(+)$. Consequently, it was highly expressed in 22 cancerous tissues and 0 paracancerous tissues, and a significant difference was indicated (Table $1, P<0.001$ ). By qRT-PCR analysis, IDH1 in cancerous tissues was upregulated relative to that in paracancerous tissues in 38 patients (Figure 2A, $P<0.001$ ). To verify the IDH1 level, Western blot analysis was performed with 10 pairs of cancerous and paracancerous tissues (Figure 2B). The results suggested that IDH1 expression was higher in cancerous tissues than in paracancerous tissues (Figure 2C, 2D, $P<0.001$ ).

\section{Diagnostic value of serum IDH1}

We assessed the serum levels of IDH1 in 67 patients with ESCC and 67 healthy controls by enzymelinked immunosorbent assay (ELISA) (Figure 3A). The mean value of IDH1 serum concentration in ESCC patients and healthy controls was $189.66 \mathrm{pg} / \mathrm{mL}$. IDH1 was significantly upregulated in patients with ESCC $(141.6 \pm 30.353 \mathrm{pg} / \mathrm{mL}$ vs. $257.8 \pm 26.609 \mathrm{pg} / \mathrm{mL}$, 
Table 1: Quantification of the expression of IDH1 in cancerous and paracancerous tissues via IHC staining

\begin{tabular}{cccccc}
\hline Group & $\boldsymbol{n}$ & $\begin{array}{c}\text { Overexpression } \\
(\boldsymbol{n})\end{array}$ & $\begin{array}{c}\text { Overexpression } \\
\text { rate (\%) }\end{array}$ & $\chi^{\mathbf{2}}$ & $\boldsymbol{P}$ value \\
\hline Cancerous tissue & 38 & 22 & $57.89 \%$ & 30.963 & $<0.001$ \\
Paracancerous tissue & 38 & 0 & $0 \%$ & & \\
\hline
\end{tabular}

Abbreviation: IHC, immunohistochemical.
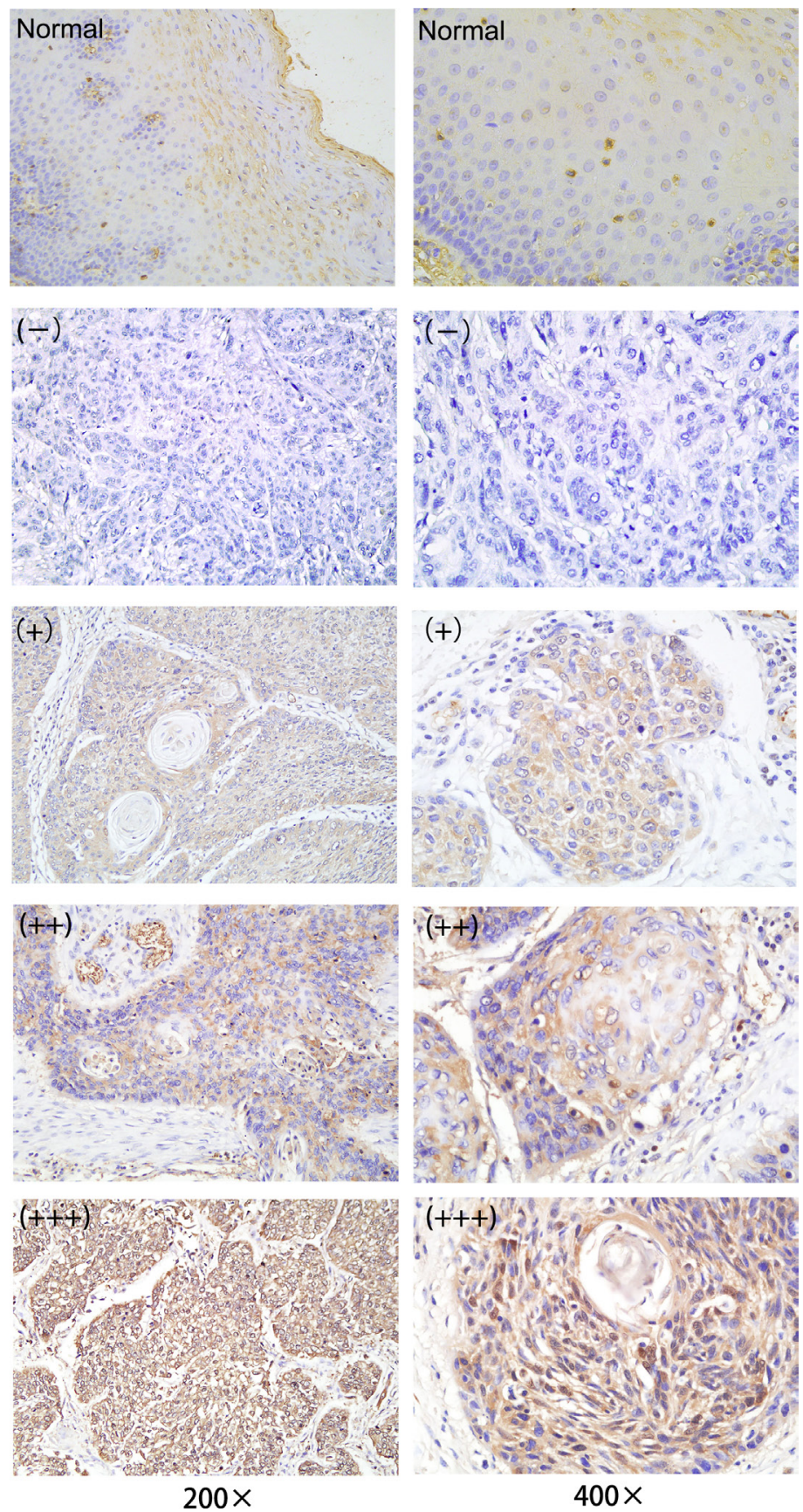

Figure 1: IDH1 expression in patients with ESCC was examined by performing immunohistochemistry. Left panel: $\times 200$. Right panel: $\times 400$. From top to bottom, in order, are as follows: paracancerous normal tissues, and $(-),(+),(++),(+++)$ of cancerous tissues. 
$P<0.001)$. We also investigated the relationship between the serum level of IDH1 and the clinicopathological features of patients with ESCC. The IDH1 expression was significantly upregulated with advanced TNM staging for $\operatorname{ESCC}(P=0.048)$. No significant links to other clinicopathological features were observed, such as age, gender, smoking, drinking, differentiation stage, T stage, and $\mathrm{N}$ stage (Table 2). The receiver operating characteristic (ROC) curve shows that the area under the ROC curve (AUC) was $0.771 \pm 0.043$ (Figure 3B). With the cut-off value set to $192.084 \mathrm{pg} / \mathrm{mL}$ (Yuden index), the sensitivity and specificity of serum IDH1 were $83.3 \%$ and $67.7 \%$, respectively. Pearson correlation coefficient analysis was used to determine the association of IHC scores in 38 frozen tissues with their paired serum expression levels (Figure 3C); the r value was $0.813(P<0.001)$.

\section{Prognostic value of IDH1}

FFPE tissues from 149 patients were used to assess IDH1 expression. A total of $83(+++), 36(++)$,
$22(+)$, and $8(-)$ were observed in accordance with the evaluation standard. The overexpression rate was 55.7 among all cases. We used the bilateral $\chi^{2}$ test to determine the correlations between IDH1 and the clinical characteristics of patients (Table 3 ). The development of differentiation $(P=0.038)$ and $\mathrm{T}$ stage $(P=0.022)$ were significantly correlated with IDH1 expression. Age, gender, smoking, drinking, N stage, and TNM stage showed no significant association with IDH1 expression. The FFPE tissues from 111 patients with their prognostic data were used for Kaplan-Meier survival analysis and Cox regression analysis. The Kaplan-Meier curve revealed that the patients with IDH1 upregulation exhibited shorter progression-free survival (PFS) and overall survival (OS) compared with patients without IDH1 upregulation (Figure 4A, 4B). Cox regression analyses were conducted to identify prognostic factors for OS and PFS in ESCC (Table 4). Univariate survival analysis indicated that $\mathrm{OS}$ and PFS are negatively correlated with IDH1 expression $(P=0.008$ and $P=0.004)$. Multivariate analysis confirmed that IDH1
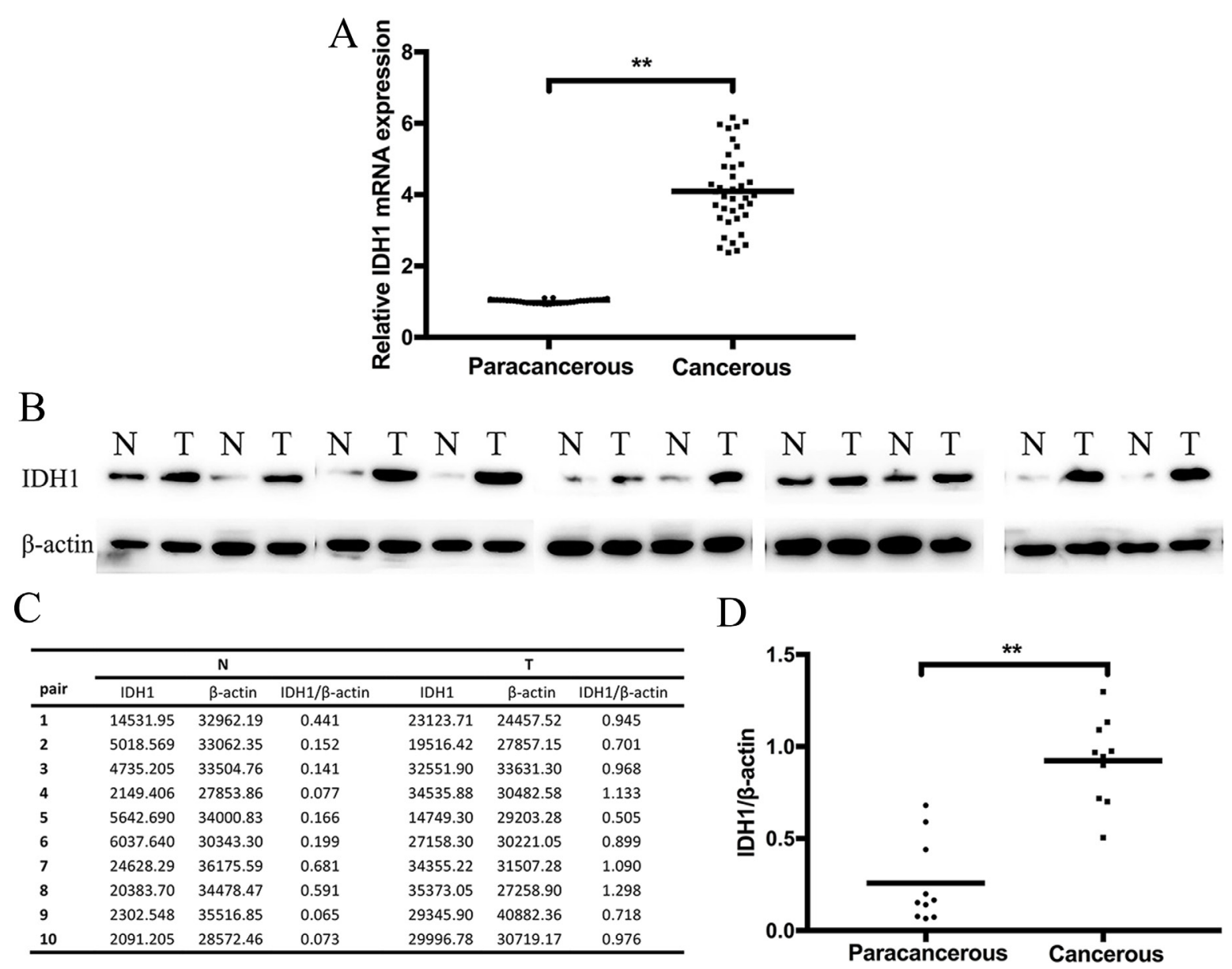

Figure 2: IDH1 expression in cancerous tissue compared with that in paracancerous tissue was detected at (A) mRNA level by RT-PCR. The $2-\Delta \Delta$ Ct method was used for calculating the IDH1 expression. The relative expression was $4.04 \pm 1.05$ vs. $1.01 \pm 0.05(P<0.001)$. (B) Protein level was detected by Western blot analysis, the intensity values of 10 pairs of tissues are shown in $(\mathbf{C})$ and the IDH1/ $\beta$-actin values of cancerous and paracancerous tissues are compared in $(\mathbf{D})$. Abbreviations: T, cancerous tissues; N, paracancerous tissues. 
Table 2: The correlation of clinicopathologic variables of ESCC with serum IDH1 expression

\begin{tabular}{|c|c|c|c|}
\hline \multirow{2}{*}{ Clinicopathological features } & \multicolumn{2}{|c|}{ IDH1 overexpression } & \multirow{2}{*}{$P^{\text {a }}$ value } \\
\hline & No $(n=24)$ & Yes $(n=43)$ & \\
\hline Age & & & 0.459 \\
\hline$<65$ & 14 & 27 & \\
\hline$\geq 65$ & 10 & 16 & \\
\hline Gender & & & 0.564 \\
\hline Female & 7 & 12 & \\
\hline Male & 17 & 31 & \\
\hline Smoking & & & 0.365 \\
\hline No & 11 & 23 & \\
\hline Yes & 13 & 20 & \\
\hline Drinking & & & 0.581 \\
\hline No & 11 & 20 & \\
\hline Yes & 13 & 23 & \\
\hline Differentiation & & & 0.922 \\
\hline Well & 7 & 12 & \\
\hline Moderate & 10 & 20 & \\
\hline Poor & 7 & 11 & \\
\hline T stage & & & 0.196 \\
\hline $\mathrm{T} 1$ & 5 & 3 & \\
\hline $\mathrm{T} 2$ & 7 & 9 & \\
\hline $\mathrm{T} 3$ & 10 & 22 & \\
\hline $\mathrm{T} 4$ & 2 & 9 & \\
\hline $\mathrm{N}$ stage & & & 0.094 \\
\hline N0 & 16 & 15 & \\
\hline N1 & 3 & 11 & \\
\hline $\mathrm{N} 2$ & 4 & 12 & \\
\hline N3 & 1 & 5 & \\
\hline TNM stage & & & $0.048 *$ \\
\hline I & 5 & 3 & \\
\hline II & 12 & 15 & \\
\hline III & 7 & 25 & \\
\hline
\end{tabular}

$P^{\text {a: }}$ Chi-square test.

Abbreviation: FFPE, formalin-fixed paraffin-embedded.

can potentially be an independent prognostic factor for OS and PFS $(P<0.001$, respectively). T stage, N stage, and adjuvant therapy were also identified as independent predictive factors for OS and PFS in patients with ESCC $(P=0.032, P=0.003$ and $P<0.001$, respectively for OS; $P=0.044, P=0.002$, and $P<0.001$, respectively for PFS). The AUC of IDH1, T stage, $\mathrm{N}$ stage, and adjuvant therapy for OS and PFS prediction are shown in Figure $4 \mathrm{C}-4 \mathrm{~J}$.

\section{Reduced growth and proliferation of ESCC cells by IDH1 inhibition with shRNA}

ESCC cell lines (Eca 109 and Eca 9706) were transfected with shRNA- IDH1. qRT-PCR and Western blot analysis were employed to evaluate the efficiency of transfection. As shown in Figure 5A and 5B, the IDH1 mRNA levels in the sh-IDH1 groups were significantly reduced relative to those in the control group (IDH1/ 
Table 3: The correlation of clinicopathologic variables of ESCC with IDH1 expression in FFPE cancerous tissues

\begin{tabular}{|c|c|c|c|}
\hline \multirow{2}{*}{$\begin{array}{c}\text { Clinicopathological } \\
\text { features }\end{array}$} & \multicolumn{2}{|c|}{ IDH1 overexpression } & \multirow{2}{*}{$P^{a}$ value } \\
\hline & No $(n=66)$ & Yes $(n=83)$ & \\
\hline Age & & & 0.869 \\
\hline$<65$ & 34 & 45 & \\
\hline$\geq 65$ & 32 & 38 & \\
\hline Gender & & & 0.741 \\
\hline Female & 28 & 38 & \\
\hline Male & 38 & 45 & \\
\hline Smoking & & & 0.743 \\
\hline No & 34 & 40 & \\
\hline Yes & 32 & 43 & \\
\hline Drinking & & & 0.328 \\
\hline No & 28 & 42 & \\
\hline Yes & 38 & 41 & \\
\hline Differentiation & & & $0.038 *$ \\
\hline Well & 32 & 26 & \\
\hline Moderate & 12 & 29 & \\
\hline Poor & 22 & 28 & \\
\hline T stage & & & $0.022 *$ \\
\hline $\mathrm{T} 1$ & 16 & 8 & \\
\hline $\mathrm{T} 2$ & 20 & 29 & \\
\hline $\mathrm{T} 3$ & 23 & 25 & \\
\hline $\mathrm{T} 4$ & 7 & 21 & \\
\hline $\mathrm{N}$ stage & & & 0.581 \\
\hline No & 31 & 34 & \\
\hline N1 & 14 & 21 & \\
\hline $\mathrm{N} 2$ & 10 & 18 & \\
\hline N3 & 11 & 10 & \\
\hline TNM stage & & & 0.183 \\
\hline I & 26 & 21 & \\
\hline II & 15 & 24 & \\
\hline III & 25 & 38 & \\
\hline
\end{tabular}

$P^{a}$ : Chi-square test.

Abbreviation: FFPE, formalin-fixed paraffin-embedded.

GADPH: $0.51 \pm 0.05$ and $0.50 \pm 0.07$ vs. $0.98 \pm 0.08$ in Eca109, $P<0.0001$, respectively; $0.55 \pm 0.06$ and $0.53 \pm 0.06$ vs. $0.99 \pm 0.06$ in Eca9706, $P<0.0001$, respectively.). Figure $4 \mathrm{C}$ and $4 \mathrm{D}$ show that the IDH1 protein level is also reduced in the transfection group (IDH1/ $\beta$-actin: $0.61 \pm 0.02$ and $0.61 \pm 0.01$ vs. $0.91 \pm 0.02$ in Eca109, $P<0.0001$, respectively; $0.51 \pm 0.01$ and $0.56 \pm 0.02$ vs. $0.90 \pm 0.02$ in Eca9706, $P<0.0001$, respectively). To determine whether knockdown of
IDH1 expression by shRNA can decrease the growth and proliferation of ESCC cells, CCK8 and clonal efficiency assays were conducted. The OD450 values of the Eca 109 and Eca 9706 cells transfected with sh-IDH1 indicated significant decreases at 48, 72 and 96h (all $P<0.01$ ) relative to those in the control groups (Figure 5C and 5D). Colony numbers of transfected Eca109 and Eca9706 cells were also significantly reduced relative to those of the control groups (all $P<0.05$, Figure 5E and 5F). 


\section{DISCUSSION}

The status of mutant $I D H 1$ in cancers has been revealed in recent years. Studies on IDHI mutations in glioma and acute myeloid leukemia (AML) have been well developed [29, 30]. However, IDH1 is not regarded as a frequent mutation in patients with ESCC according to 3 whole genome sequencing or whole exome sequencing analyses conducted among a Chinese population, as well as a study conducted among a Japanese population [31-34]. Consequently, the current study focused only on the expression of wild-type IDH1 in ESCC.

In the present study, IDH1 expression is higher in cancerous tissues than in paracancerous tissues (mRNA: $P<0.001$; IHC: $P<0.001$; Western blot analysis: $P<0.001)$. Despite the individual difference in IDH1 expression in different patients, IDH1 was more highly expressed in cancerous tissues than in paracancerous tissues for one patient. This finding indicates that IDH1 can potentially be a good biomarker for ESCC.

Previous study has confirmed the diagnostic value of IDH1 for NSCLC [27].

We found that IDH1 could act as a potential diagnostic biomarker for ESCC. The result indicated higher IDH1 expression in patients with ESCC than in
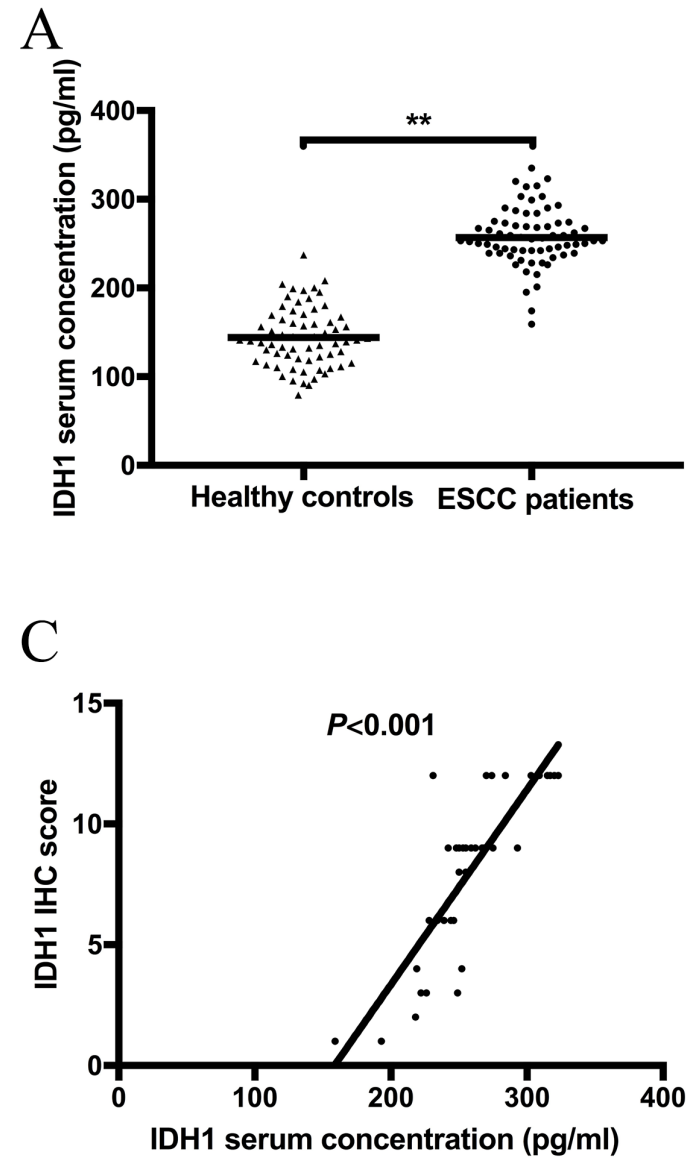

healthy controls. The AUC value was determined to be $0.771 \pm 0.043$. The Pearson correlation coefficient indicated that the IDH1 expression in frozen cancerous tissue was significantly associated with serum expression. Consequently, serum IDH1 could be a non-invasive diagnostic biomarker for ESCC. Notably, IDH1 expression in serum was positively associated with TNM stage $(P=0.048)$; this link suggests that IDH1 can act as an oncogene in ESCC development. We hypothesized that elevated IDH1 expression in serum can be illustrated in the following aspects. First, cancer cells upregulate cellular IDH1 in response to rapid proliferation and increased ROS. Second, vigorous metabolism and tissue necrosis enhance the permeability of the cytomembrane, leading to the release of IDH1 into circulation. Third, the degradative pathway and efficiency of IDH1 may be transformed in cancer cells at odds with normal cells.

In this study, we explored the prognostic value of IDH1 in ESCC. The upregulation of IDHI was related to the reduction in OS and PFS, as shown by the KaplanMeier curve. Further univariate and multivariate analyses indicated that IDH1 was an independent prognostic factor for OS and PFS. The AUC values of $0.646(P=0.011)$ and $0.653(P=0.016)$ suggested that IDH1 yielded a significant prognostic value with high sensitivity and

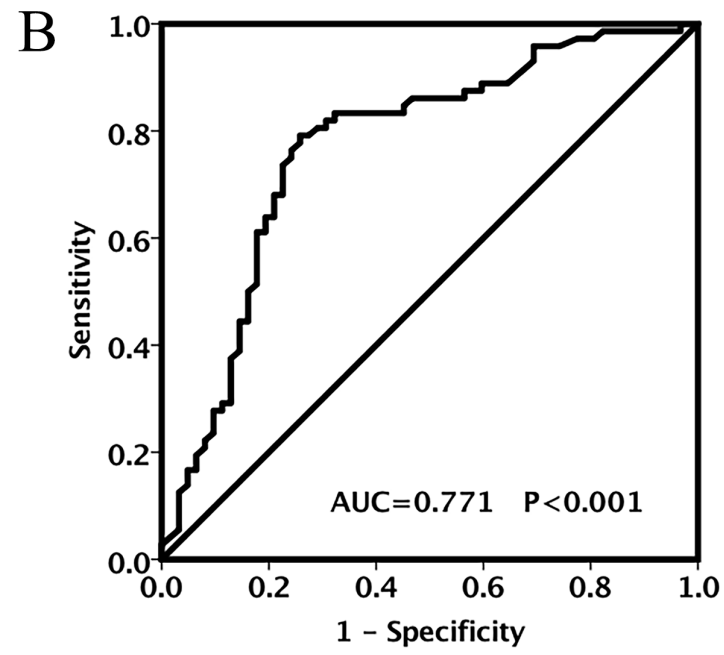

Figure 3: (A) IDH1 serum concentration in ESCC patients and healthy controls detected by ELISA. (B) ROC-AUC curve analysis for the diagnostic value of IDH1. 
Table 4: Univariate and multivariate analyses of prognostic variables

\begin{tabular}{|c|c|c|c|c|c|c|c|c|}
\hline \multirow[b]{2}{*}{ Variable } & \multirow{2}{*}{$\begin{array}{c}\text { OS } \\
\text { Univariate } \\
\text { analysis } \\
P \text { value }\end{array}$} & \multicolumn{3}{|c|}{$\begin{array}{c}\text { OS } \\
\text { Multivariate } \\
\text { Analysis }\end{array}$} & \multirow{2}{*}{$\begin{array}{c}\text { PFS } \\
\text { Univariate } \\
\text { analysis } \\
P \text { value }\end{array}$} & \multicolumn{3}{|c|}{$\begin{array}{c}\text { PFS } \\
\text { Multivariate } \\
\text { analysis }\end{array}$} \\
\hline & & $P$ value & HR & $95 \% \mathrm{CI}$ & & $P$ value & HR & $95 \% \mathrm{CI}$ \\
\hline Gender (Famale VS. Male) & 0.884 & 0.870 & 1.043 & $0.630-1.727$ & 0.710 & 0.896 & 0.970 & $0.611-1.539$ \\
\hline Age $(<65$ vs. $\geq 65)$ & 0.854 & 0.545 & 0.844 & $0.486-1.463$ & 0.959 & 0.658 & 0.893 & $0.543-1.471$ \\
\hline Smoking (Yes vs. No) & 0.672 & 0.062 & 1.941 & $0.967-3.898$ & 0.715 & 0.164 & 1.569 & $0.832-2.959$ \\
\hline Drinking (Yes vs. No) & 0.483 & 0.277 & 1.479 & $0.730-2.993$ & 0.338 & 0.096 & 1.728 & $0.908-3.289$ \\
\hline T stage & $0.002 *$ & $0.032 *$ & & & $0.001 *$ & $0.044 *$ & & \\
\hline $\mathrm{T} 1$ & & & 1.000 & Ref. & & & 1.000 & Ref. \\
\hline $\mathrm{T} 2$ & & $0.023^{*}$ & 3.186 & $1.170-8.675$ & & $0.025^{*}$ & 2.759 & $1.138-6.688$ \\
\hline $\mathrm{T} 3$ & & $0.001 *$ & 5.766 & $2.119-15.69$ & & $0.001 *$ & 4.827 & $1.988-11.72$ \\
\hline $\mathrm{T} 4$ & & $0.038 *$ & 2.417 & $1.033-6.586$ & & $0.045^{*}$ & 2.367 & $1.109-5.779$ \\
\hline N stage & $0.001 *$ & $0.003 *$ & & & $0.001 *$ & $0.002 *$ & & \\
\hline N0 & & & 1.000 & Ref. & & & 1.000 & Ref. \\
\hline N1 & & $0.004 *$ & 2.779 & $1.391-5.554$ & & $0.001 *$ & 2.927 & $1.543-5.552$ \\
\hline N2 & & $0.004 *$ & 2.951 & $1.406-6.194$ & & $0.012 *$ & 2.369 & $1.211-4.633$ \\
\hline N3 & & $<0.001 *$ & 6.672 & $2.833-15.71$ & & $<0.001^{*}$ & 5.987 & $2.690-13.32$ \\
\hline Differentiation & 0.080 & 0.059 & & & 0.137 & 0.164 & & \\
\hline Well & & & 1.000 & Ref. & & & 1.000 & Ref. \\
\hline Moderate & & $0.006^{*}$ & 2.537 & $1.307-4.921$ & & $0.016^{*}$ & 2.043 & $1.140-3.663$ \\
\hline Poor & & $0.023^{*}$ & 2.527 & $1.138-5.610$ & & $0.048^{*}$ & 2.041 & $1.008-4.132$ \\
\hline $\begin{array}{l}\text { Adjuvant therapy } \\
\text { (Yes vs. No) }\end{array}$ & $0.023^{*}$ & $<0.001 *$ & 2.697 & $1.551-4.690$ & $0.009 *$ & $<0.001^{*}$ & 2.876 & $1.714-4.826$ \\
\hline IDH1 & $0.008^{*}$ & $<0.001^{*}$ & 3.256 & $1.785-5.939$ & $0.004 *$ & $<0.001^{*}$ & 3.536 & $2.036-6.141$ \\
\hline
\end{tabular}

Abbreviations: OS, overall survival; PFS, progression-free survival; CI: confidence interval.

specificity. Likewise, $\mathrm{N}$ stage and adjuvant therapy were relevant to the prognosis of ESCC. Correlations between IDH1 expression and clinicopathological features were analyzed. Unlike the outcome from the serum samples, the expression levels were associated with differentiation and $\mathrm{T}$ stage, which may be attributed to discrepant and insufficient sampling. Similarly, this outcome demonstrates the potential of IDH1 as an oncogene in ESCC. The results of CCK8 and clonal efficiency assays showed that ESCC cells with decreased IDH1 possessed inhibited growth and proliferation.

The mechanisms of IDH1 regulation and effects on cancer have not been elaborated. RNA interference in IDH1 inhibits the proliferation of NSCLC cells and suppresses tumor growth in a xenograft model [35]. Moreover, siRNA knockdown of IDH1 significantly decreases the proliferative ability of the AML cell line with wild-type IDH1 [25]. IDH significantly affects antioxidation by supplying NADPH, which is essential for the production of GSH reductase and regeneration of thioredoxin (Trx) [36]. GSH and Trx are important antioxidative systems protecting the cell from oxidative damage by scavenging the ROS and influencing cell survival $[37,38]$. New evidence has demonstrated that main cellular antioxidant systems, such as the GSH and Trx systems, promote the growth of cancer cells and suppress the immune response [18]. Trx inhibits cell apoptosis signaling both by scavenging intracellular ROS in cooperation with the GSH system and interfering with the normal functions of apoptosis signal-regulating kinase 1 (ASK1) and p38 mitogen-activated protein kinase [39]. IDH also regulates apoptosis induced by tumor necrosis factor- $\alpha$ and chemotherapy in Hela cells, facilitating the development of a sensitizer to anticancer drugs [40].

Studies with large samples and are warranted to validate our findings, and further studies can be conducted to detect the detailed mechanisms of IDH1 in ESCC. With an enhanced understanding of IDH1 in ESCC, we can elucidate the biological behaviors of ESCC and use such information. In addition, the harmful effects of radiotherapy and several anticancer drugs on the DNA of cancer cells are realized by ROS. IDH1 may be a good predictor for chemotherapy or radiotherapy. 
Therefore, IDH1 is significantly upregulated in ESCC tissue and serum. IDH1 shows potential as a biomarker for both diagnosis and prognosis of ESCC.

\section{MATERIALS AND METHODS}

\section{Specimen collection and patient enrollment}

To evaluate the relationship of IDH1 expression with the status of diagnosis, 38 ESCC cancer tissue samples from tissue blocks and 67 serum samples from patients with ESCC were obtained from the Qilu Hospital of Shandong University from February 2015 to June 2015. Tissue samples were collected from patients who provided serum samples. For control groups, adjacent noncancerous tissues from the aforementioned 38 patients and serum from 67 healthy volunteers were collected. In addition, 111
FFPE cancer tissue samples from patients who underwent subtotal esophagectomy and esophagogastric anastomosis plus regional lymph node dissection in 2009 were used for clinical/pathological factors and survival analysis.All specimens were pathologically confirmed, and none of the patients received neoadjuvant therapy (chemotherapy and/ or radiotherapy). A total of 40 (36.04\%) patients were alive, whereas $71(63.96 \%)$ patients died during follow-up. The median survival time was 40 months (12-80 months). Data on patient demographics,smoking and drinking history, histologic grade, tumor stage, grade of differentiation, and number of dissected lymph nodes were collected. Tumor stages were assessed according to the Seventh Edition of the Cancer Staging Manual of the American Joint Committee on Cancer. This study was evaluated and approved by the Ethics Committee of Qilu Hospital of Shandong University. A written consent was obtained from each patient.
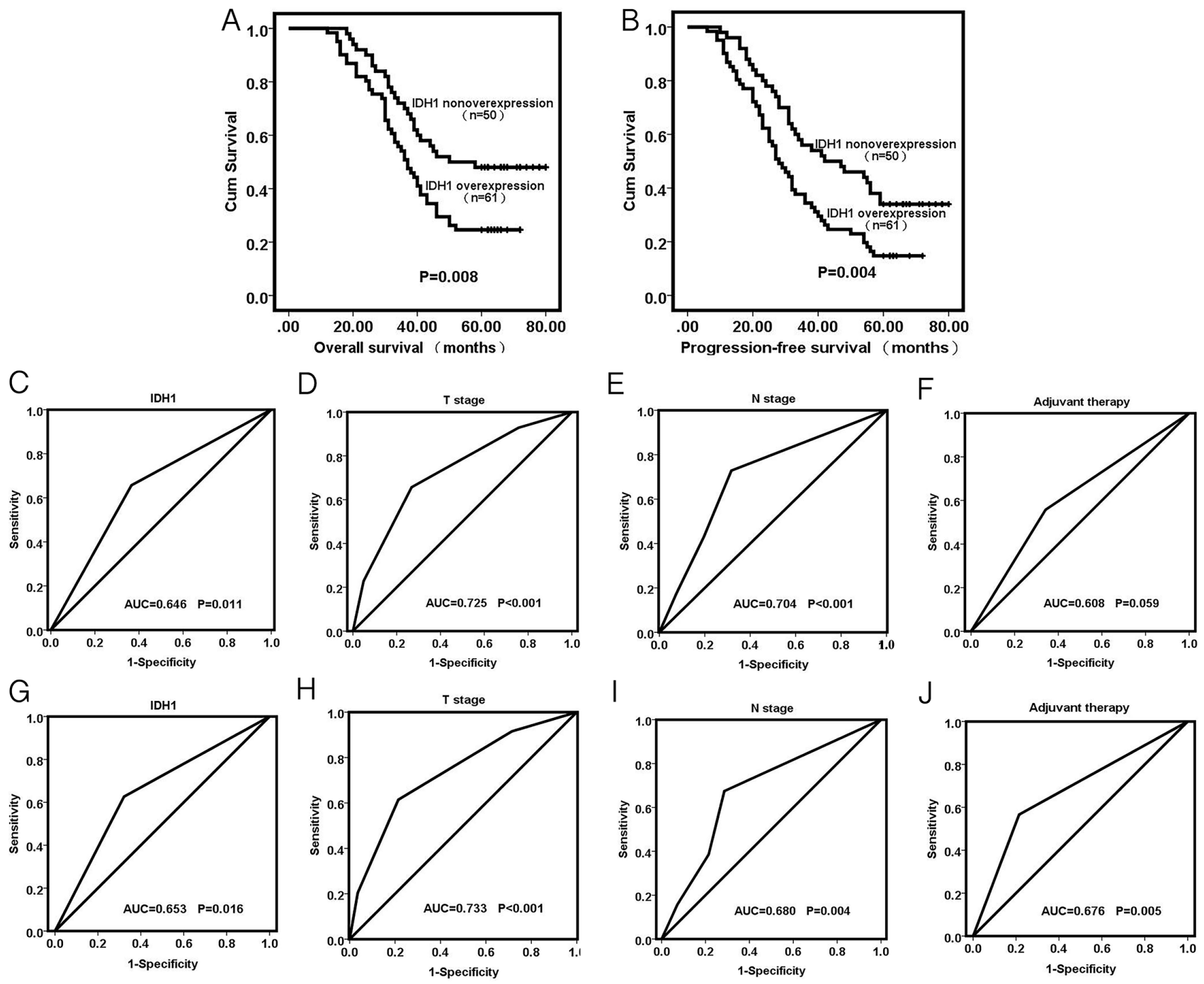

Figure 4: (A and B) Kaplan-Meier analysis for overall survival and progression-free survival of ESCC patients with IDH1 non-overexpression or overexpression. (C-F) ROC-AUC curve analysis for OS prediction of IDH1, T stage, N stage and adjuvant therapy. (G-J) ROC-AUC curve analysis for PFS prediction of IDH1, T stage, N stage and adjuvant therapy. 


\section{IHC}

The esophageal cancer tissues were fixed in $10 \%$ formalin overnight and then embedded in paraffin following the standard procedure. Deparaffinization using xylene and rehydration was conducted. Antigen retrieval was performed using a citrate-EDTA buffer (2 mM EDTA, 10 mM citric acid, 0.05\% Tween 20, pH 6.2). To deactivate intrinsic peroxidase, sections were incubated with hydrogen peroxide. We then applied diluted anti-IDH1 antibody (1:60; Proteintech, China) to the sections at $4^{\circ} \mathrm{C}$ overnight. Samples incubated with PBS instead of a primary antibody were used as negative controls. After a biotin-labeled secondary antibody was added, the sections were reacted with horseradish peroxidase (HRP)-labeled streptavidin. The sections were stained with 3,3'-diaminobenzidine or DAB, followed by counterstaining with hematoxylin. They were finally visualized under a microscope.

Five $\times 400$ fields were randomly selected, and 2 pathologists independently performed the evaluation. Scores were determined by the intensity of the dye color
A

$\mathrm{D}$

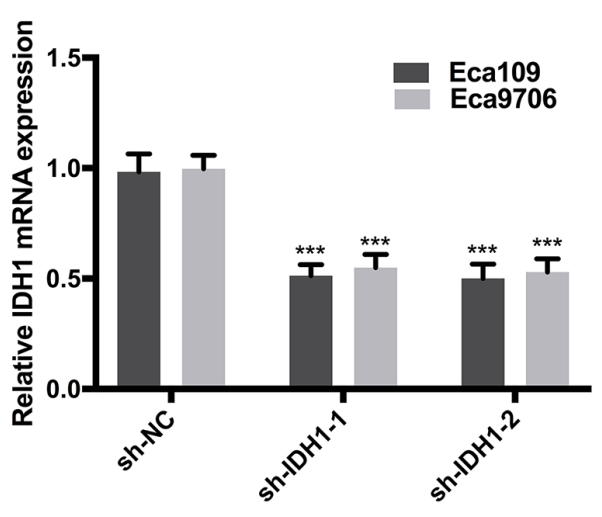

Eca109

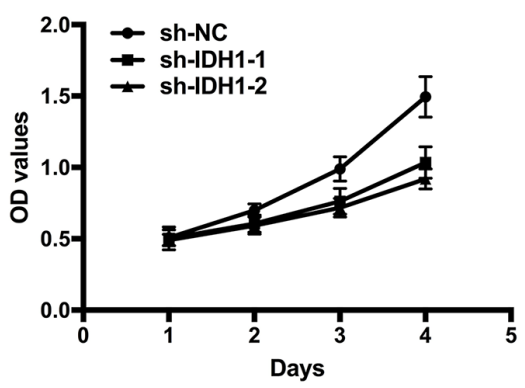

$\mathrm{E}$
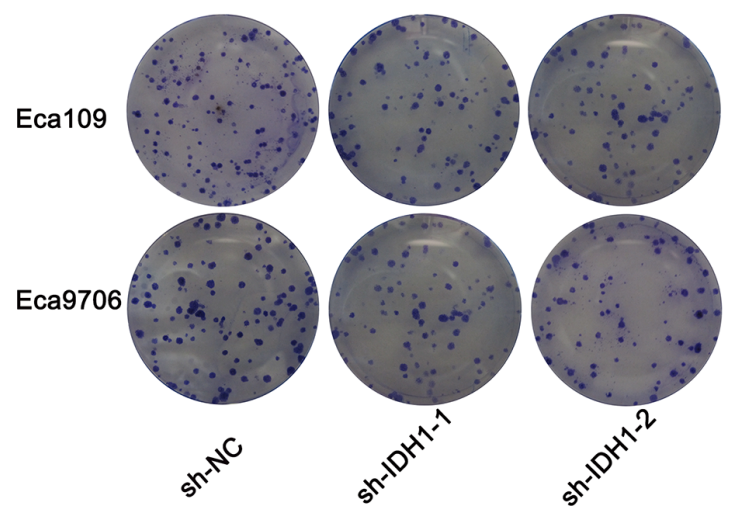

B

$\mathrm{C}$
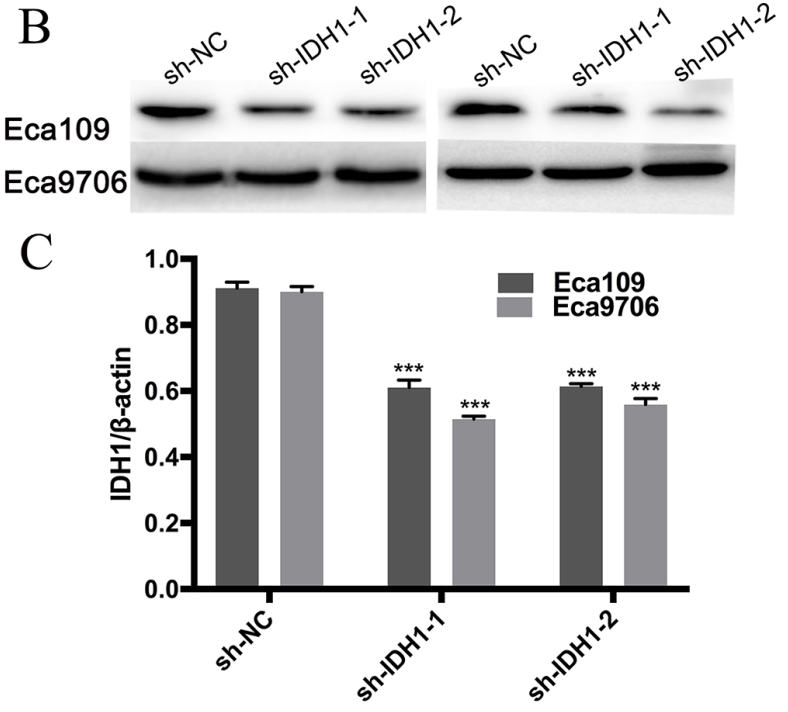

Eca9706

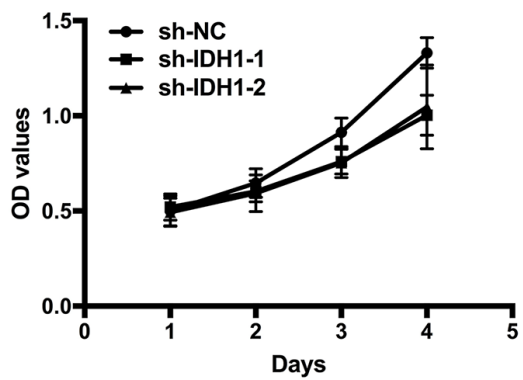

F

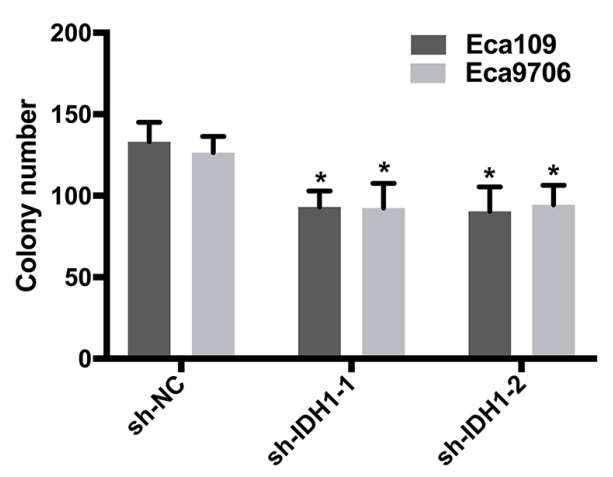

Figure 5: Expression of IDH1 in Eca109 and Eca9706 was reduced by transfection of sh-IDH1-1 and sh-IDH1-2 at mRNA level (A) and protein level (B and C). The OD values (D) and clony numbers (E and F) were decreased in sh-IDH1-1 and sh-IDH1-2 groups. 
and the quantity of positive cells. The intensity of the dye color was classified as weak, moderate, and intense (denoted by 1,2 , and 3, respectively). Grading of the number of positive cells was based on the following: $0(<5 \%), 1(5 \%-25 \%), 2(25 \%-50 \%), 3(51 \%-75 \%)$, and $4(>75 \%)$. The percentage of positive cells and the staining intensity of each sample were multiplied to obtain the weighted scores. The 2 grades were added, and the sections were assigned to one of the following levels: $0-1$ score $(-), 2-4$ scores $(+), 5-8$ scores $(++)$, and 9-12 scores $(+++)$. The overexpressed value was denoted by $(+++)$.

\section{qRT-PCR}

Total RNA was extracted from fresh tissues or cells by using TRIzol Reagent (Invitrogen, USA) in accordance with the manufacturer's instructions. The IDH1 expression of each sample was assessed using the Bio-Rad Single Color Real-Time PCR system (BioRad, USA) with SYBR Green Real Time PCR Master Mix (TOYOBO, Osaka, Japan). The synthesized primer sequences (Sangon Biotech, China) were as follows: IDH1:5'-GTCGTCATGCTTATGGGGAT-3' (forward primer), 5'-CAACACCACCACCTTCTTCA-3' (reverse primer); GAPDH: 5'-GAAGGTCGGAGTCAACGGAT-3' (forward primer), 5'-CCTGGAAGATGGTGATGGGAT-3' (reverse primer). The IDH1 expression was calculated using the 2- $\Delta \Delta \mathrm{Ct}$ method, where $\Delta \mathrm{Ct}=\mathrm{Ct}_{\mathrm{IDH} 1}-\mathrm{Ct}_{\mathrm{GADPH}}$ and $\Delta \Delta \mathrm{Ct}=\Delta \mathrm{Ct}_{\text {test }}-\Delta \mathrm{Ct}_{\text {control }}$. All assays were performed in triplicate. The data are presented as the mean $\pm \mathrm{SD}$.

\section{Western blot analysis}

Radioimmunoprecipitation assay (RIPA) buffer (50 mM Tris, $150 \mathrm{mM} \mathrm{NaCl}, 1 \%$ Triton $\mathrm{X}-100,1 \%$ sodium deoxycholate, $0.1 \%$ SDS, sodium orthovanadate, sodium fluoride, EDTA, leupeptin) and phenylmethylsulfonyl fluoride (PMSF, Beyotime,China) were used to extract protein from tissue homogenate or cells. Every $100 \mathrm{mg}$ of tissue required $1 \mathrm{ml}$ of RIPA buffer and $10 \mu \mathrm{L}$ of PMSF. The supernatant was stored at $-20^{\circ} \mathrm{C}$ for later use. Extracts containing an identical amount of protein were separated by electrophoresis on $10 \%$ polyacrylamide gels. Proteins were transferred to a nitrocellulose membrane and blocked in 5\% defatted dry milk. The membrane was incubated with the primary IDH1 antibody and $\beta$-actin antibody (1:100, Proteintech, China) and then with HRP-conjugated secondary antibodies. The bands of antigen-antibody complexes were detected using a chemiluminescence detection system (EMD Millipore, USA).

\section{ELISA}

Serum samples were separated from blood and stored at $-80^{\circ} \mathrm{C}$. The protein concentrations of IDH1 were measured using a commercially available ELISA kit (Proteintech, China). Approximately $100 \mu \mathrm{L}$ of each sample was added to a 96-well plate coated with the IDH1 antibody for a $2 \mathrm{~h}$ reaction. Subsequently, $100 \mu \mathrm{L}$ of HRPconjugated antibody was added and then incubated for $1 \mathrm{~h}$. A substrate solution was added, and the absorbance of each of the samples at 450 and $630 \mathrm{~nm}$ was detected using the xMark Microplate Spectrophotometer (Bio-Rad Laboratories, Inc., USA). The assay was performed in triplicate, and the average values were used for statistical analysis.

\section{Cell culture and transfection}

Human ESCC cell lines Eca109 (CCTCC) and Eca9706 (ATCC) were cultured in RPMI 1640 (Gibco, USA) supplemented with $10 \%$ fetal bovine serum and incubated in a $5 \% \mathrm{CO}_{2}$ atmosphere at $37^{\circ} \mathrm{C}$. Plasmidmediated shRNA was used for RNA interference. pGPU6/ GFP/Neoplasmid was provided by Shanghai GenePharma Biologic Co. Ltd., China: sh-IDH1-1 (Target sequence: 5'-TAACTTTGAAGAAGGTGGTGG-3'), sh-IDH1-2 (Target sequence: 5'-GGTATGAGCATAGGCTCAT CG-3'), sh-NC (Target sequence: 5'-GTTCTCCGAAV GTGTCACGT). Transfection was conducted using Lipofectamine 2000 Reagent (Invitrogen, USA). $0.8 \mathrm{mg} / \mathrm{mL}$ of G418 was used for selecting stably transfected cells.

\section{Cell viability assays}

Logarithmically growing cells were seeded in 96-well plates at a density of 2000 cells per well. Cell survival and proliferation were determined using the Cell Counting Kit 8 (CCK-8) (Dojindo, Japan). The medium was changed into a $100 \mu \mathrm{L}$ fresh medium and a $10 \mu \mathrm{L}$ CCK-8 solution for $1 \mathrm{~h}$ incubation when the OD value had to be measured. Varioskan Flash (Thermo Scientific, Finland) was used to detect OD values at $450 \mathrm{~nm}$. The average of the 5 wells represented the result of each sample.

\section{Clonal efficiency assay}

Cells were trypsinized into a single cell suspension and then cultured for $2 \mathrm{wk}$ at a density of 200 per well. Colonies fixed with methanol were stained with crystal violet. Clones containing at least 50 cells were considered as one formation. Nonsense shRNA-transfected cells were used as controls.

\section{Statistical analysis}

Statistical analyses were performed with SPSS ver. 23.0. $P<0.05$ was considered statistically significant. Differences in the mRNA and protein expression levels of IDH1 between cancerous and paired paracancerous tissues were analyzed by paired Student's $t$-test. The Wilcoxon test was applied to analyze the difference in serum samples between patients with ESCC and healthy individuals. All samples were classified into high or low 
levels according to the cut-off value (the mean value of all participants). The Pearson correlation coefficient was determined to evaluate the relationship of the IDH1 expression in frozen tissue with that in serum. The correlations of the IDH1 in tissue or serum samples with the clinicopathological factors were determined using the bilateral $\chi^{2}$ test. The diagnostic value of serum IDH1 in ESCC was obtained using the ROC curve and the AUC. Survival curves were derived from the Kaplan-Meier method. The hazard ratios were assessed by univariate and multivariate Cox survival analyses. The AUC was also provided for the Cox regression models. For assays in vitro, the difference between each pair among sh-NC, sh-IDH2-1, and sh-IDH2-2 was evaluated using ANOVA with post-hoc Tukey test.

\section{ACKNOWLEDGMENTS}

None.

\section{CONFLICTS OF INTEREST}

The authors declare no competing interests.

\section{GRANT SUPPORT}

This study was supported by the National Natural Science Foundation of China (Grant No. 81572958).

\section{REFERENCES}

1. Napier KJ, Scheerer M, Misra S. Esophageal cancer: A Review of epidemiology, pathogenesis, staging workup and treatment modalities. World J Gastrointest Oncol. 2014; 6:112-120.

2. Siegel RL, Miller KD, Jemal A. Cancer statistics, 2016. CA Cancer J Clin. 2016; 66:7-30.

3. IIITorre LA, Bray F, Siegel RL, Ferlay J, Lortet-Tieulent J, Jemal A. Global cancer statistics, 2012. CA Cancer J Clin. 2015; 65:87-108.

4. Pennathur A, Gibson MK, Jobe BA, Luketich JD. Oesophageal carcinoma. Lancet. 2013; 381:400-412.

5. Hanash SM, Baik CS, Kallioniemi O. Emerging molecular biomarkers - blood-based strategies to detect and monitor cancer. Nat Rev Clin Oncol. 2011; 8:142-150.

6. Zhang J, Zhu Z, Liu Y, Jin X, Xu Z, Yu Q, Li K. Diagnostic value of multiple tumor markers for patients with esophageal carcinoma. PLoS One. 2015; 10:e0116951.

7. Hjelmeland A, Zhang J. Metabolic, autophagic, and mitophagic activities in cancer initiation and progression. Biomed J. 2016; 39:98-106.

8. Hanahan D, Weinberg RA. Hallmarks of cancer: the next generation. Cell. 2011; 144:646-674.

9. Pavlova NN, Thompson CB. The Emerging Hallmarks of Cancer Metabolism. Cell Metab. 2016; 23:27-47.
10. Dang L, Yen K, Attar EC. IDH mutations in cancer and progress toward development of targeted therapeutics. Ann Oncol. 2016; 27:599-608.

11. Hausinger RP. FeII/alpha-ketoglutarate-dependent hydroxylases and related enzymes. Crit Rev Biochem Mol Biol. 2004; 39:21-68.

12. Dang CV. Links between metabolism and cancer. Genes Dev. 2012; 26:877-890.

13. Lee SH, Jo SH, Lee SM, Koh HJ, Song H, Park JW, Lee WH, Huh TL. Role of NADP+-dependent isocitrate dehydrogenase (NADP+-ICDH) on cellular defence against oxidative injury by gamma-rays. Int J Radiat Biol. 2004; 80:635-642.

14. de Oliveira MF, Amoedo ND, Rumjanek FD. Energy and redox homeostasis in tumor cells. Int J Cell Biol. 2012; 2012:593838.

15. Gorrini C, Harris IS, Mak TW. Modulation of oxidative stress as an anticancer strategy. Nat Rev Drug Discov. 2013; 12:931-947.

16. Winkler BS, DeSantis N, Solomon F. Multiple NADPHproducing pathways control glutathione (GSH) content in retina. Exp Eye Res. 1986; 43:829-847.

17. Lee SM, Koh HJ, Park DC, Song BJ, Huh TL, Park JW. Cytosolic NADP(+)-dependent isocitrate dehydrogenase status modulates oxidative damage to cells. Free Radic Biol Med. 2002; 32:1185-1196.

18. Benhar M, Shytaj IL, Stamler JS, Savarino A. Dual targeting of the thioredoxin and glutathione systems in cancer and HIV. J Clin Invest. 2016; 126:1630-1639.

19. Cairns RA, Mak TW. Oncogenic isocitrate dehydrogenase mutations: mechanisms, models, and clinical opportunities. Cancer Discov. 2013; 3:730-741.

20. Lu C, Ward PS, Kapoor GS, Rohle D, Turcan S, AbdelWahab O, Edwards CR, Khanin R, Figueroa ME, Melnick A, Wellen KE, O'Rourke DM, Berger SL, et al. IDH mutation impairs histone demethylation and results in a block to cell differentiation. Nature. 2012; 483:474-478.

21. Dang L, White DW, Gross S, Bennett BD, Bittinger MA, Driggers EM, Fantin VR, Jang HG, Jin S, Keenan MC, Marks KM, Prins RM, Ward PS, et al. Cancer-associated IDH1 mutations produce 2-hydroxyglutarate. Nature. 2009; 462:739-744.

22. Waitkus MS, Diplas BH, Yan H. Isocitrate dehydrogenase mutations in gliomas. Neuro Oncol. 2016; 18:16-26.

23. McKenney AS, Levine RL. Isocitrate dehydrogenase mutations in leukemia. J Clin Invest. 2013; 123:3672-3677.

24. Fujii T, Khawaja MR, DiNardo CD, Atkins JT, Janku F. Targeting isocitrate dehydrogenase (IDH) in cancer. Discov Med. 2016; 21:373-380.

25. Ward PS, Patel J, Wise DR, Abdel-Wahab O, Bennett BD, Coller HA, Cross JR, Fantin VR, Hedvat CV, Perl AE, Rabinowitz JD, Carroll M, Su SM, et al. The common feature of leukemia-associated IDH1 and IDH2 mutations is a neomorphic enzyme activity converting alpha- 
ketoglutarate to 2-hydroxyglutarate. Cancer Cell. 2010; 17:225-234.

26. Banks RE, Dunn MJ, Hochstrasser DF, Sanchez JC, Blackstock W, Pappin DJ, Selby PJ. Proteomics: new perspectives, new biomedical opportunities. Lancet. 2000; 356:1749-1756.

27. Sun N, Chen Z, Tan F, Zhang B, Yao R, Zhou C, Li J, Gao Y, Liu Z, Tan X, Zhou F, He MY, Shao K, et al. Isocitrate dehydrogenase 1 is a novel plasma biomarker for the diagnosis of non-small cell lung cancer. Clin Cancer Res. 2013; 19:5136-5145.

28. Chen C, Peng H, Huang X, Zhao M, Li Z, Yin N, Wang X, Yu F, Yin B, Yuan Y, Lu Q. Genome-wide profiling of DNA methylation and gene expression in esophageal squamous cell carcinoma. Oncotarget. 2016; 7:4507-4521. doi: 10.18632/oncotarget.6607.

29. Louis DN, Perry A, Reifenberger G, von Deimling A, Figarella-Branger D, Cavenee WK, Ohgaki H, Wiestler OD, Kleihues P, Ellison DW. The 2016 World Health Organization Classification of Tumors of the Central Nervous System: a summary. Acta Neuropathol. 2016; 131:803-820.

30. Shafer D, Grant S. Update on rational targeted therapy in AML. Blood Rev. 2016; 30:275-283.

31. Gao YB, Chen ZL, Li JG, Hu XD, Shi XJ, Sun ZM, Zhang F, Zhao ZR, Li ZT, Liu ZY, Zhao YD, Sun J, Zhou CC, et al. Genetic landscape of esophageal squamous cell carcinoma. Nat Genet. 2014; 46:1097-1102.

32. Song Y, Li L, Ou Y, Gao Z, Li E, Li X, Zhang W, Wang J, Xu L, Zhou Y, Ma X, Liu L, Zhao Z, et al. Identification of genomic alterations in oesophageal squamous cell cancer. Nature. 2014; 509:91-95.

33. Zhang L, Zhou Y, Cheng C, Cui H, Cheng L, Kong P, Wang J, Li Y, Chen W, Song B, Wang F, Jia Z, Li L, et al. Genomic analyses reveal mutational signatures and frequently altered genes in esophageal squamous cell carcinoma. Am J Hum Genet. 2015; 96:597-611.

34. Sawada G, Niida A, Uchi R, Hirata H, Shimamura T, Suzuki Y, Shiraishi Y, Chiba K, Imoto S, Takahashi Y, Iwaya T, Sudo T, Hayashi T, et al. Genomic Landscape of Esophageal Squamous Cell Carcinoma in a Japanese Population. Gastroenterology. 2016; 150:1171-1182.

35. Tan F, Jiang Y, Sun N, Chen Z, Lv Y, Shao K, Li N, Qiu B, Gao Y, Li B, Tan X, Zhou F, Wang Z, et al. Identification of isocitrate dehydrogenase 1 as a potential diagnostic and prognostic biomarker for non-small cell lung cancer by proteomic analysis. Mol Cell Proteomics. 2012; 11:M111 008821.

36. Jo SH, Son MK, Koh HJ, Lee SM, Song IH, Kim YO, Lee YS, Jeong KS, Kim WB, Park JW, Song BJ, Huh TL. Control of mitochondrial redox balance and cellular defense against oxidative damage by mitochondrial NADP+dependent isocitrate dehydrogenase. J Biol Chem. 2001; 276:16168-16176.

37. Lu J, Holmgren A. Thioredoxin system in cell death progression. Antioxid Redox Signal. 2012; 17:1738-1747.

38. Lu SC. Regulation of glutathione synthesis. Mol Aspects Med. 2009; 30:42-59.

39. Ueda S, Masutani H, Nakamura H, Tanaka T, Ueno M, Yodoi J. Redox control of cell death. Antioxid Redox Signal. 2002; 4:405-414.

40. Kil IS, Kim SY, Lee SJ, Park JW. Small interfering RNAmediated silencing of mitochondrial NADP+-dependent isocitrate dehydrogenase enhances the sensitivity of HeLa cells toward tumor necrosis factor-alpha and anticancer drugs. Free Radic Biol Med. 2007; 43:1197-1207. 